\title{
A TUTELA MULTINÍVEL DE DIREITOS FUNDAMENTAIS NUMA PERPECTIVA DIALÓGICA: A PROTEÇÃO REGIONAL E NACIONAL DA PRESUNÇÃO DE INOCÊNCIA
}

\author{
THE MULTILEVEL PROTECTION OF FUNDAMENTAL RIGHTS IN A DIALOGICAL \\ PERSPECTIVE: THE REGIONAL AND NATIONAL GUARANTEE OF THE \\ PRESUMPTION OF INNOCENCE
}

\author{
Flávia Danielle Santiago Lima ${ }^{1}$ \\ Drailton Ferreira Vieira ${ }^{2}$
}

\section{RESUMO}

Como a garantia do princípio da presunção de inocência em nível regional nos Tratados Internacionais de Direitos Humanos ratificados pelo Brasil e na Constituição Brasileira de 1988 pode ser articulada para a maior proteção deste direito fundamental? Para responder a esta pergunta, propõe-se a discussão desta proteção em seus múltiplos níveis - nacional, regional, local - analisando sua inserção nos tratados que versam sobre os direitos humanos, a fim de mostrar suas intersecções e distinções no que se refere à positivação no ordenamento brasileiro. A pesquisa parte de uma abordagem teórica, com o método hipotético-dedutivo, em que se pretende organizar as premissas em torno da tutela multinível de direitos fundamentais e suas possibilidades dialógicas, para estabelecer uma compreensão do princípio da não-culpabilidade. Sustenta-se a hipótese de que a conjunção dos aspectos garantistas do sistema regional e brasileiro de proteção de direitos ampara um não-retrocesso na garantia da presunção da inocência, de sorte que a prisão somente deve ocorrer a partir do trânsito em julgado da sentença penal condenatória.

Palavras-chave: Tutela Multinível de Direitos; Pacto de San Jose da Costa Rica; Constituição Federal; Presunção de Inocência; Trânsito em Julgado.

\begin{abstract}
How can the guarantee of the principle of presumption of innocence at the regional level in the International Treaties of Human Rights ratified by Brazil and in the Brazilian Constitution of 1988 be articulated for the greater protection of this fundamental right? In order to answer this question, it is proposed to discuss this protection at its multiple levels - national, regional, local - by analyzing its insertion in human rights treaties, in order to show their intersections and distinctions with regard to positivation in the Brazilian order. The research starts from a theoretical approach, with the hypothetico-deductive method, in which it is intended to organize the premises around the multilevel guardianship of fundamental rights and their

\footnotetext{
${ }^{1}$ Mestre e Doutora em Direito Público pela Faculdade de Direito do Recife (FDR) da Universidade Federal de Pernambuco/UFPE. Pós-doutorado na Universitat de València. Professora permanente dos Programas de PósGraduação em Direito da FDR/UFPE (Mestrado e Doutorado). Professora da Universidade Católica de Pernambuco (UNICAP) e da Universidade de Pernambuco (FCAP/UPE, campus Benfica/Recife). Advogada da União.flavia-santiago@uol.com.br (81) 992233554
}

\footnotetext{
${ }^{2}$ Mestrando noPrograma de Pós-Graduação em Direito da FDR/UFPE drailtonk@yahoo.com.br
} 
dialogical possibilities, to establish an understanding of the principle of non-culpability. It is hypothesized that the conjunction of the guarantor aspects of the regional and Brazilian system of protection of rights supports a non-retrocession in guaranteeing the presumption of innocence, so that the imprisonment should only occur after the final sentence of the criminal sentence conviction.

\section{Keywords}

Multinível of Rights; Pact of San Jose of Costa Rica; Federal Constitution; Presumption of Innocence; Transit in Judgment

\section{Introdução: oscilações e controvérsias na garantia do estado de inocência}

O princípio da presunção de inocência ou princípio da não-culpabilidade ou, ainda, estado de inocência (PACCELLI, 2017), considerado um dos princípios reitores da limitação ao jus puniendi estatal, é uma garantia histórica do cidadão, que remonta aos primeiros documentos de proteção dos direitos humanos, e conta com ampla positivação nas ordens jurídicas global, regional e local.

No Brasil, referido princípio está previsto no artigo $5^{\circ}$, inciso LVII, da Constituição Federal de 1988 (CRFB), que considera culpado o réu apenas após o trânsito em julgado da sentença penal condenatória.

A despeito destas múltiplas previsões em graus distintos, a interpretação e aplicação deste dispositivo constitucional, principalmente nos julgamentos proferidos pelo Supremo Tribunal Federal (STF), tem sido alvo de controvérsias e oscilações.

Após a promulgação da CFRB, algumas decisões proferidas pelo STF provocaram mais dúvidas que certezas em relação ao alcance hermenêutico dos termos presunção de inocência e trânsito em julgado. No julgamento dos pedidos de Habeas Corpus, os ministros do STF - em decisões monocráticas ou turmárias - apresentavam entendimentos distintos em relação ao início do cumprimento da pena após a condenação proferida pelas instâncias inferiores. 
O epicentro do debate ora encaminhava a interpretação jurídica favorável ao cumprimento irrestrito do texto constitucional, ora propunha sua relativização, ensejando entendimentos diametralmente opostos. É possível destacar dois momentos importantes desta querela hermenêutica. O primeiro foi o julgamento do HC 84.078, de 2009, que firmou jurisprudência favorável ao cumprimento da pena somente após o trânsito em julgado. $\mathrm{O}$ segundo foi a decisão proferida após a análise do HC 126.292, de 2016, que alterou novamente o entendimento da corte, possibilitando o início do cumprimento da pena após a decisão em segundo grau, prolatada pelo órgão de segundo grau.

Estes dois momentos em que o STF atuou de forma decisiva ainda repercutem nos debates quanto ao aspecto garantista da Constituição de 1988. As expectativas do mundo jurídico se voltam agora para o julgamento do mérito das Ações Declaratórias de Constitucionalidade que foram propostas pelo Partido Ecológico Nacional e Ordem dos Advogados do Brasil, questionando a mudança de entendimento do STF na votação do HC 126.292.

Todos estes acontecimentos desencadearam um amplo debate acerca do que caracteriza a presunção de inocência e sua relevância para a ordem jurídica brasileira, sobretudo quanto à sua aplicação a partir das disposições legislativas do direito penal e processual penal em suas repercussões para a efetividade dos direitos fundamentais.

Isto porque, para além do direito interno, a garantia da presunção de inocência é prevista nos Tratados Internacionais de Direitos Humanos ratificados pelo Brasil e devidamente incorporados à ordem nacional. A presunção de inocência constituir-se-ia, deste modo, uma garantia em múltiplos níveis, dependente de suas disposições materiais e mecanismos de implementação.

O objetivo deste trabalho é discutir esta proteção em seus múltiplos níveis - nacional, regional, local - analisando sua inserção nos tratados que versam sobre os direitos humanos, a fim de mostrar suas intersecções e distinções no que se refere à positivação no ordenamento brasileiro. O estudo parte de uma abordagem teórica, com o método hipotético-dedutivo, em que se pretende organizar as premissas em torno da tutela multinível de direitos fundamentais e suas possibilidades dialógicas, para estabelecer uma compreensão da presunção de inocência no Pacto de San Jose da Costa Rica e na Constituição Federal de 1988. A pesquisa é apoiada por um levantamento bibliográfico e documental. Parte-se da hipótese de que a conjunção dos aspectos garantistas do sistema regional e brasileiro de proteção de direitos ampara um 
não-retrocesso na garantia da presunção da inocência, de sorte que a prisão somente deve ocorrer a partir do trânsito em julgado da sentença penal condenatória.

\section{Tutela multinível de direitos humanos: em busca de convergência e diálogos entre o sistema regional e nacional}

A convergência de ordens jurídicas nacionais e supranacionais é um fenômeno acentuado pelo período posterior a Segunda Guerra Mundial, com a ascensão das organizações internacionais e recrudescimento da imperatividade das declarações de direitos humanos. Tratava-se do reconhecimento da necessidade de garantias que ultrapassassem a relação cidadão vs Estado Nacional, mas que integrassem os seres humanos para além das organizações políticas.

Resgata-se, assim, a celebre discussão em torno das divergências e similitudes em torno das expressões direitos humanos e/ou direitos fundamentais, a partir de diversos pontos de observação. Frequentemente, emprega-se a denominação direitos humanos àquelas disposições asseguradas nos tratados internacionais, enquanto os direitos fundamentais referem-se às normas de direito interno (no caso, constitucionais).

Bruce Ackerman sustenta diversas formas de articulação entre as constituições e os tratados internacionais, assentada na duplicidade de percepção na função dos documentos nacionais: tratados que se convertem em constituições e constituições que passam a ser similares a tratados. O primeiro caso decorre, muitas vezes, de um processo histórico. $\mathrm{O}$ segundo ocorre quando há modificações interpretativas, em que as constituições contam com funções mais características de tratados, com certa flexibilidade.

Neste último caso, constituições que possuem maior abertura para articulação de novas fontes demonstram alcançar a finalidade que se espera desse novo modo de enxergar o constitucionalismo (ACKERMAN, 1997, p.775-778).

Para Perez Luño (1995, p. 30-31), o reconhecimento nos ordenamentos jurídicos, em âmbito nacional ou internacional, seria o elemento identificador dos direitos fundamentais, enquanto "conjunto de poderes e instituições que, em cada momento histórico, concretizam a dignidade, liberdade e igualdade humanas, que devem ser reconhecidas positivamente".

No caso brasileiro, a Constituição Federal de 1988 adota semânticas diversas para as distintas proteções jurídicas. As referências ao âmbito internacional são geralmente 
acompanhadas pela menção aos "direitos humanos", como no art. 4, II, ao passo que os direitos nela reconhecidos são denominados de "Direitos Fundamentais" (Título II, art. $5^{\circ}, \S$ $1^{\circ}$ ), direitos e liberdades constitucionais (art. $5^{\circ}$, LXXI) ou direitos e garantias individuais (art. 60, §4, IV). A despeito de polêmicas doutrinárias e jurisprudenciais, tem-se uma cláusula de abertura na previsão do art. $5^{\circ}, \S 2^{\circ}$, que estabelece a interação entre o direito nacional e os tratados internacionais de direitos humanos., ao prever que os direitos e garantias expressos na Constituição "não excluem outros decorrentes do regime e dos princípios por ela adotados, ou dos tratados internacionais em que a República Federativa do Brasil seja parte". E, caso estes sejam aprovados "em cada Casa do Congresso Nacional, em dois turnos, por três quintos dos votos dos respectivos membros, serão equivalentes às emendas constitucionais" ( $\operatorname{art.} 5^{\circ}, \S 3^{\circ}$ ).

Para Flávia Piovesan (2014), o constituinte atribuiria a estes direitos hierarquia de norma constitucional e aplicabilidade imediata; de modo que seria possível classificar os direitos fundamentais em três grupos: (a) expressos na Constituição; b) implícitos, decorrentes do regime e dos princípios adotados pela Carta constitucional; e c) decorrentes dos tratados internacionais subscritos pelo Brasil.

Reconhecida a imperatividade dos tratados internacionais de direitos humanos, podese falar de uma proteção multinível destes, nos termos propostos por Aída Torres para explicação do modelo europeu, na coexistência de três esferas garantidoras, correspondentes ao binômio declaração de direitos $e$ corte respectiva: nacional, supranacional e internacional (TORRES PÉREZ, 2009, p. 1-3).

No caso brasileiro, tem-se o reconhecimento, de três níveis, por expressa vinculação e previsão constitucional: (a) nacional, representado pelo sistema constitucional; (b) regional, relativos a Ordem dos Estados Americanos e seus instrumentos; (c) global, representado pela Organização das Nações Unidas.

Estas múltiplas proteções, contudo, dependem das articulações entre estes diversos níveis, no que se refere às suas normas materiais e garantias processuais.

É nestes casos que exsurge a necessidade de convergência e diálogos entre estas diversas ordens, que não pode implicar em hierarquias ou superposições, especialmente quando se trata de regulamentações quanto ao mesmo objeto. Defende-se um processo de interdependência entre os âmbitos local e internacional que, se bem-sucedido, implica no fortalecimento de ambos (Slaughter et al., 2006, p. 36). 
Diversas são as construções que abordam estas interações, em diversos âmbitos e instâncias estatais. O transconstitucionalismo, de Marcelo Neves, traz uma proposta que vai além do diálogo entre cortes, alcançando as compreensões dos poderes legislativo e executivo, além dos atores sociais. Abrange questões nacionais e supranacionais de natureza constitucional e, especialmente, atinentes aos direitos fundamentais.

O transconstitucionalismo aponta para o fato de que surgem cada vez mais questões que poderão envolver instâncias estatais, internacionais, supranacionais e transnacionais (arbitrais), assim como instituições jurídicas locais nativas, na busca da solução de problemas tipicamente constitucionais (NEVES, 2014, p.194).

Certamente que a postura cooperativa encontra dificuldades, seja porque alguns aspectos da proteção dos direitos humanos não são objeto de consenso transnacional, porque mesmo posturas convergentes são capazes de gerar distintas interpretações quanto à mesma posição jurídica, sem prejuízo da natureza dinâmica do direito e interpretações decorrentes, que afasta visões estáticas geradas por uma hermenêutica de convergência (JACKSON, 2010, p. 66-68). Para além destes obstáculos, a convergência implica, para o hermeneuta, num compromisso de conformação da interpretação constitucional aos consensos do direito internacional/ transnacional (JACKSON, 2010, p. 42).

Neste sentido, indaga-se: como a articulação em níveis regional e local podem assegurar a maior tutela de direitos? É justamente para responder a esta questão, parte-se da análise da presunção de inocência no Pacto de San Jose da Costa Rica e na Constituição Federal de 1988, a partir das construções da dogmática penal brasileira.

\section{Da proteção supranacional: a presunção de inocência no Pacto de San Jose da Costa Rica}

O princípio da presunção de inocência surge do próprio direito natural, abalizado nos alicerces de uma sociedade que reverencia os valores éticos, morais, mas especialmente os valores humanos, fundamentalmente aqueles que têm como cerne a dignidade da pessoa humana.

Todo homem é presumido inocente até que ele tenha sido declarado culpado; se ele está julgado indispensável prendê-lo, todo rigor que não seria 
necessário para a segurança de sua pessoa deve ser severamente reprimido pela Lei. (TOURINHO FILHO, 2000, p. 65).

A Declaração dos Direitos do Homem e do Cidadão de 1789, catalisadora dos ideais da Revolução Francesa, que representa sua perspectiva universalizante ${ }^{3}$, considerada um dos primeiros documentos de direitos humanos, também estabelecia o princípio da nãoculpabilidade em seu corpo, em seu art. $9^{\circ}$ :

Todo homem é considerado inocente, até ao momento em que, reconhecido como culpado, se julgar indispensável a sua prisão: todo o rigor desnecessário, empregado para a efetuar, deve ser severamente reprimido pela lei (Declaração dos Direitos do Homem e do Cidadão)

Abria-se, com isso, naquele período, uma grande mudança do sistema processual penal na Europa, que entusiasmaria muitos outros países inseridos na tradição do constitucionalismo liberal.

Já no contexto posterior à Segunda Guerra Mundial, a Declaração Universal dos Direitos Humanos da ONU - Organização das Nações Unidas, de 1948, traz a "positivação internacional dos direitos mínimos dos seres humanos, em complemento aos propósitos das Nações Unidas", assegurando "liberdades fundamentais de todos, sem distinção de sexo, raça, língua ou religião" (MAZZUOLI, 2017, p. 83).

O princípio da presunção de inocência é insculpido no art. 11, §1 da Declaração, sob a qual "ninguém será condenado à pena de ofensa, tendo o direito de ser presumido inocente até provado a culpa de acordo com a Lei” (TOURINHO FILHO, 2000, p. 65). Trata-se de garantia voltada a assegurar ao réu uma condenação de "acordo com a lei, em julgamento público no qual lhe tenham sido asseguradas todas as garantias necessárias à sua defesa (MAZZUOLI, 2017, p. 87). Não são estabelecidos, contudo, parâmetros de identificação do momento em que o réu é considerado inocente, de sorte que seria necessário esperar o trânsito em julgado para que a culpabilidade seja definida ou suprimida.

Depois desta fase, foram instituídos mais três documentos de direitos humanos, no plano global e regional, devidamente ratificados pelo Brasil e contemplativos do princípio da não-culpabilidade. O primeiro foi o Pacto Internacional dos Direitos Civis e Políticos. Este

\footnotetext{
${ }^{3}$ As Revoluções Liberais do século XVIII culminaram com a estipulação de Declarações de Direitos, como a da Virgínia (Estados Unidos, 1776) e Declaração Universal dos Direitos do Homem e do Cidadão (França, 1789). A primeira restringia-se à enunciação de direitos frente ao estado, ao passo que a segunda notabilizou-se pelo seu caráter universalizante e relevância simbólica. (BOBBIO, 1992, p. 88-97)
} 
começou a ser constituído no ano de 1949 pela Assembleia Geral das Nações Unidas. No ano de 1954 foi apresentada a minuta na Assembleia Geral das Nações Unidas, para finalmente ser concluído e adotado em 1966. O texto dele traz mais detalhamentos acerca dos direitos da declaração, porém não se limitando apenas a eles, trazendo uma gama maior de direitos.

Quanto aos artigos do Pacto, pode-se resumidamente dividi-lo em dois segmentos: o primeiro elencando os direitos fundamentais, restritos à esfera civil-política (classificados na primeira dimensão), e o segundo segmento dedicado aos mecanismos de implementação do Pacto.

No Brasil, o Pacto mencionado teve sua promulgação pelo Decreto $n^{\circ} 592$, de 6 de julho de 1992 e traz a previsão do indigitado princípio em seu artigo 14, $\S 2^{\circ}$ item 5, onde se diz que "toda pessoa acusada de um delito terá direito a que se presuma sua inocência enquanto não for legalmente comprovada sua culpa", corroborando ainda mais com as garantias penais daqueles submetido ao jus puniendi estatal.

O importante deste documento é que não há previsão do elemento interpretativo "trânsito em julgado" como parâmetro hermenêutico axiológico do afastamento do estado de inocência do cidadão. Aqui se preserva a lógica do ônus da prova, em que não cabe ao acusado provar sua inocência, uma que esta já está pressuposta de antemão, cabendo ao acusador envidar os esforços nos sentidos de apresentar as provas, que serão validadas ou não durante todo o processo penal.

Outro documento importante é a Convenção Americana de Direitos Humanos, também chamada de Pacto de San Jose da Costa Rica, assinada em 22 de novembro de 1969, na cidade de San José, na Costa Rica, e ratificado pelo Brasil em setembro de 1992, através do Decreto $\mathrm{n}^{\circ}$ 678, de 06 de novembro de 1992.

O documento é composto por 82 artigos, incluindo as disposições transitórias. No geral, o Pacto trata das principais questões relacionadas aos direitos humanos, tal como estão consignados na Declaração Universal dos Direitos Humanos, de 1948. Neste sentido, os temas da liberdade de expressão, do respeito à vida e aos princípios básicos da convivência humana, se fazem presentes em ambos os documentos. A diferença é que o Pacto de San Jose aprofunda os temas que aparecem na Declaração dos Direitos Humanos, inclusive proibindo a escravidão e a servidão humanas.

O comprometimento do Pacto de San Jose da Costa Rica com os direitos fundamentais ampara-se em suas clausulas materiais, mas também em suas normas de interpretação, como as insculpidas em seus arts. 29 e 30, ao disporem que: 
Artigo 29. Normas de interpretação

Nenhuma disposição desta Convenção pode ser interpretada no sentido de: a. permitir a qualquer dos Estados Partes, grupo ou pessoa, suprimir o gozo e exercício dos direitos e liberdades reconhecidos na Convenção ou limitálos em maior medida do que a nela prevista;

b. limitar o gozo e exercício de qualquer direito ou liberdade que possam ser reconhecidos de acordo com as leis de qualquer dos Estados Partes ou de acordo com outra convenção em que seja parte um dos referidos Estados;

c. excluir outros direitos e garantias que são inerentes ao ser humano ou que decorrem da forma democrática representativa de governo; e

d. excluir ou limitar o efeito que possam produzir a Declaração Americana dos Direitos e Deveres do Homem e outros atos internacionais da mesma natureza.

Artigo 30. Alcance das restrições

As restrições permitidas, de acordo com esta Convenção, ao gozo e exercício dos direitos e liberdades nela reconhecidos, não podem ser aplicadas senão de acordo com leis que forem promulgadas por motivo de interesse geral e com o propósito para o qual houverem sido estabelecidas.

Por sua vez, o princípio da não-culpabilidade está previsto no artigo $8^{\circ}, \S 2^{\circ}$, no qual se afirma que "toda pessoa acusada de um delito tem direito a que se presuma sua inocência, enquanto não for legalmente comprovada sua culpa" (OEA, 1960).

Referido artigo ainda traz importantes afirmações que remetem à defesa do devido processo legal, elemento fundamental para configurar o reconhecimento da presunção de inocência. Destas, destaca-se alínea " $h$ " do artigo $8^{\circ}, \S 2^{\circ}$, que dispõe que a pessoa tem o "direito de recorrer da sentença a juiz ou tribunal superior" (Convenção Americana de Direitos Humanos de 1969 - Pacto de San José da Costa Rica). O direito de se recorrer a uma instância superior também converge para a mesma lógica da previsão constitucional brasileira, na qual a presunção de inocência se estende até a decisão prolatada pelo órgão máximo, no caso brasileiro, o Supremo Tribunal Federal, conformando uma situação onde o acusado não tem mais como recorrer da sentença, uma vez que não há mais uma corte para a qual se possa apelar e, consequentemente, recorrer da sentença, como se verá adiante.

\section{A proteção (forte?) nacional: presunção de inocência até o trânsito em julgado na} Constituição Federal de 1988

No direito brasileiro, o princípio da presunção de inocência está previsto na Constituição de 1988, especificamente no art. 5, inciso LVII, ao dispor que "ninguém será 
considerado culpado até o trânsito em julgado de sentença penal condenatória" (BRASIL, 1988)

Cândido Rangel Dinamarco (1994) menciona que o princípio surgiu no fim do século XVIII em contraposição ao sistema inquisitório, onde o acusado era desprovido de qualquer garantia. Esta nova concepção era bem diferente do que se preceituava desde o século XII, onde o acusado era considerado culpado até que se provasse o contrário. Este sistema inquisitório concebe a aplicação da pena como uma retaliação ao inimigo, provocando sedimentando distinções entre quem merece ser punido e quem tem a prerrogativa da proteção do amigo. É o que Zaffaroni expõe ao afirmar que "o estrangeiro, o estanho, o inimigo, o hostis, era quem carecia de direitos em termos absolutos, quem estava fora da comunidade" (ZAFFARONI, 2007, p. 22)

Embora considere a denominação presunção de inocência imprecisa, recorrendo à tese do ônus da prova ao acusador, Dinamarco (1994) reitera o princípio constitucional expresso no artigo $5^{\circ}$, inciso LVII.

Ao comentar a mudança de entendimento do STF, favorável ao início do cumprimento da pena após a condenação em segunda instância, Badaró (2016) afirma que tal decisão é equivocada, além de restringir indevidamente e inadmissivelmente a garantia constitucional do artigo $5^{\circ}$, LVII, que estabelece como marco final da presunção de inocência o "transito em julgado" da sentença penal condenatória, e não "até a confirmação da sentença em segundo grau".

Ainda de acordo com o autor, não há margem exegética para que a expressão seja interpretada, como o foi pelo STF, no sentido de que o acusado é presumido inocente, mesmo iniciando o cumprimento da pena, decorrente da sentença de segundo grau, ainda que ele possa interpor recurso para o STF ou STJ (BADARÓ, 2016).

A este respeito, Alexandre de Moraes (2015, p. 136) faz uma importante defesa da presunção de inocência, como um dos princípios basilares do Estado de Direito, da garantia processual penal, assim como instrumento eficaz para se obter a tutela da liberdade pessoal. Desta forma "há a necessidade de o Estado comprovar a culpabilidade do indivíduo, que é constitucionalmente presumido inocente, sob pena de voltarmos ao total arbítrio estatal".

Com estas palavras, o autor confirma o Pacto de San José da Costa Rica e os tratados internacionais que tratam da questão da presunção da inocência, já mencionados no título anterior. No Brasil, consagrado no art. $5^{\circ}$ da Constituição Federal, o princípio da presunção de 
inocência tomou seu próprio sentido. Estudado e avaliado por muitos processualistas penais, ganhou interpretações próprias e características diferentes.

Na visão de Paulo Rangel, não há em que se falar em presunção de inocência e sim em declaração de inocência, pois a Constituição Federal não presume que ninguém seja inocente, mas declara que ninguém será considerado culpado até o trânsito em julgado de sentença penal condenatória:

Primeiro não adotamos a terminologia presunção de inocência, pois, se o réu não pode ser considerado culpado até o trânsito em julgado da sentença penal condenatória, também não pode ser presumidamente inocente. A Constituição não presume a inocência, mas declara que ninguém será considerado culpado até o trânsito em julgado de sentença penal condenatória (art. $5^{\circ}$, LVII). Em outras palavras, uma coisa é a certeza da culpa, outra, bem diferente, é a presunção da culpa. Ou, se preferirem, a certeza da inocência ou a presunção da inocência (RANGEL, 2010, p. 24).

Para Amilton Bueno de Carvalho (2001, p. 51), a presunção de inocência é pressuposição. Conforme o autor, mesmo que este princípio não estivesse normatizado na Declaração dos Direitos do Homem, ou em nossa Carta Magna, assim mesmo ele seria garantia fundamental, pois, segundo ele "o princípio da presunção de inocência não precisa estar positivado em lugar nenhum: é pressuposto (...)".

Aury Lopes Júnior (2006, p. 190) chama a atenção para o fato de que não cabe ao acusado provar a acusação que recai sobre ele, pois no processo penal não pode haver a inversão do ônus da prova. Neste sentido, "gravíssimo erro é cometido por numerosa doutrina (e rançosa jurisprudência), ao afirmar que a defesa incumbe a prova de uma alegada excludente". Para o autor, "nada mais equivocado, principalmente se compreendido o dito até aqui. A carga do acusador é de provar o alegado; logo demonstrar que alguém (autoria) praticou um crime". Desta forma, prossegue o autor, "incumbe ao acusador provar a presença de todos os elementos que integram a tipicidade, a ilicitude e a culpabilidade e, logicamente, a inexistência das causas de justificação”. (LOPES JUNIOR, 2006, 190).

O princípio da presunção de inocência é um dever de tratamento. Neste sentido, a "presunção de inocência impõe um verdadeiro dever de tratamento (na medida em que exige que o réu seja tratado como inocente), que atua em duas dimensões: interna ao processo e exterior a ele" (LOPES JUNIOR, 2008, p. 187). 
Eugênio Pacelli de Oliveira fala em estado ou situação jurídica de inocente. Para ele, este princípio impõe ao Estado a observância e respeito a duas regras específicas ao acusado, uma com relação ao tratamento e outra de fundo probatório:

[...] tratamento, segundo o qual o réu, em nenhum momento do inter persecutório, pode sofrer restrições pessoais fundadas exclusivamente na possibilidade de condenação, e a outra, de fundo probatório, a estabelecer que todos os ônus da prova relativa à existência do fato e à sua autoria devem recair exclusivamente sobre a acusação. (OLIVEIRA, 2015, p. 33).

Esse dever impõe ao juiz que a carga de provas seja obrigatoriamente do acusador, afinal se o réu é inocente ele não precisa provar nada. Com efeito, garante-se constitucionalmente ao acusado o direito de não ter que produzir provas contra si mesmo. $\mathrm{Na}$ dimensão externa ao processo a presunção de inocência irá atuar como um limitador, a fim de que o réu seja protegido da publicidade que na maioria das vezes é extremamente abusiva, contribuindo para a estigmatização precoce do acusado:

Significa dizer que a presunção de inocência (e também as garantias constitucionais a imagem, dignidade e privacidade) deve ser utilizada como verdadeiros limites democráticos à abusiva exploração midiática em torno do fato criminoso e do próprio processo judicial. O bizarro espetáculo montado pelo julgamento midiático deve ser coibido pela eficácia da presunção de inocência (LOPES JUNIOR, 2008, p. 191-192).

Zaffaroni (2012, p. 307) se refere a esta situação utilizando o termo criminologia midiática, que "cria a realidade de um mundo de pessoas decentes frente a uma massa de criminosos, identificada através de estereótipos que configuram um eles separado do resto da sociedade, por serem um conjunto de diferentes e maus".

No tirocínio cria-se uma presunção de culpa contrária ao acusado, que terá desde o início da persecução criminal uma carga de contraprovar sua inocência, alterando-se os primados mais subliminares do processo penal constitucionalizado, que por sua vez deve ser o norte do Estado Democrático de Direito.

Luigi Ferrajoli destaca que o importante é que todos os inocentes sejam, sem exceção, protegidos.

[...] é um princípio fundamental de civilidade, fruto de uma opção garantista a favor da tutela da imunidade dos inocentes, ainda que para isso tenha-se que pagar o preço da impunidade de algum culpável. Isso porque, ao corpo 
social, lhe basta que os culpados sejam geralmente punidos, pois o maior interesse é que todos os inocentes, sem exceção, estejam protegidos. (FERRAJOLI, 1995, p. 549)

Não pode haver pena sem culpabilidade, de sorte que a "pena não pode ultrapassar a medida da culpabilidade - proporcionalidade na culpabilidade", como uma "expressão de justiça material peculiar ao Estado democrático de Direito delimitadora de toda a responsabilidade penal”. (PRADO, 2017, p. 247-248)

Esta relação entre a culpabilidade e legalidade penal, "reafirma o caráter inviolável do respeito à dignidade do ser humano. É diretriz garantista, essencial à afirmação do Estado Democrático de Direito" (PRADO, 2017, 248).

O princípio da presunção de inocência, fundante do direito processual penal, estabelece assim parâmetros para que a dignidade humana seja respeitada, sendo um estado em que se encontra o acusado até ser declarado culpado. Uma forma de tratamento que internamente impõe ao juiz que a carga de provas seja obrigatoriamente do acusador; e externamente tem o importante dever de atuar como um limitador. O acusado necessita ser protegido da publicidade que, na maioria das vezes, é extremamente abusiva em relação à imputação da culpa, provocando a estigmatização precoce da pessoa.

Para dirimir quaisquer dúvidas, a legislação processual penal, após a modificação promovida pela Lei $\mathrm{n}^{\circ} 12.403$, de 2011, reforça a relação entre presunção de inocência e necessidade de trânsito em julgado, em seu art. 283:

Art. 283. Ninguém poderá ser preso senão em flagrante delito ou por ordem escrita e fundamentada da autoridade judiciária competente, em decorrência de sentença condenatória transitada em julgado ou, no curso da investigação ou do processo, em virtude de prisão temporária ou prisão preventiva.

Portanto, no que tange ao principio da presunção de inocência, a análise dos tratados internacionais ratificados pelo Brasil na sua relação com o enunciado do artigo $5^{\circ}$, inciso LVII da Constituição da República Federativa do Brasil de 1988, mostra que neles, a expressão trânsito em julgado não está especificada. Este termo só aparece na constituição. Por conseguinte, a Carta Magna de 88 se revela um texto cuja garantia ao cidadão é mais extensa no tocante à presunção de inocência. 


\section{Conclusões: o não-retrocesso na garantia das liberdades individuais como princípio- vetor das relações entre sistemas de proteção de direitos fundamentais}

A partir da análise comparativa dos dispositivos encontrados nos Tratados Internacionais de Direitos Humanos que o Brasil ratificou, é possível perceber que há uma precisão maior em nossa Constituição no que concerne à previsão de culpabilidade, assim como em relação ao inicio do cumprimento da pena. Sua positivação, tal como aparece no artigo $5^{\circ}$, inciso LVII, representa um novo (e mais garantista) patamar em relação aos documentos chancelados pelo governo brasileiro em parceria com outras nações. Pode-se perceber que estes acordos não preveem em seu corpo o elemento "trânsito em julgado" como parâmetro de aferição da inocência do cidadão submetido ao "jus puniendi" Estatal.

Neste sentido, a CF-88 se apresenta como um texto cuja garantia ao cidadão é mais extenso. Não é muito lembrar que, segundo a revolução iluminista, ele advém do próprio direito natural, fundamentado nas bases de uma sociedade livre, democrática, que respeita os valores éticos, morais, mas principalmente os valores pessoais, aqueles que têm por essência a proteção da pessoa humana e que a Constituição Democrática Brasileira se sobrepõe a todos os Tratados de Direitos Humanos que os prevê.

Entretanto, a questão que se coloca no momento presente refere-se aos desdobramentos decorrentes da decisão proferida pelo Supremo Tribunal Federal, que no ano de 2016, considerou a possibilidade do início do cumprimento da pena após a condenação do réu em segunda instância. $\mathrm{O}$ debate acerca da constitucionalidade de tal decisão remete ao entendimento que deve ser dado ao próprio texto constitucional, quando se refere à defesa da presunção de inocência, atrelando sua plausibilidade ao esgotamento de todos os recursos, até a última instância.

Ao que tudo indica, os ministros do Supremo Tribunal Federal ainda não deram a última palavra em relação ao trânsito em julgado e sua relação com o início do cumprimento da pena e o princípio da não-culpabilidade. É provável que os debates se concentrem na definição jurídica destes termos, assim como na exigência, por parte da sociedade, de uma justiça mais ágil, que puna de forma exemplar os indivíduos que cometem crimes, principalmente aqueles relacionados às diversas formas de corrupção.

É de se acreditar que a temática da relativização da presunção de inocência ainda será alvo de muitos debates e controvérsias, quer no âmbito jurídico, quer nos meios acadêmicos. O conturbado cenário político pelo qual o Brasil atravessa enseja a possibilidade de algumas 
reviravoltas em termos da atuação do Supremo Tribunal Federal na determinação da jurisprudência em relação ao trânsito em julgado. Isto não que dizer que elas necessariamente ocorrerão, apenas que os embates ideológicos ora encampados pelos atores políticos possuem um grande potencial de influenciar a tomada de decisões acerca da introdução de novos entendimentos do texto constitucional.

Contudo, é neste momento que uma proteção multinível, atrelada ao comprometimento num diálogo entre as diversas fontes do direito, como previsto no texto constitucional em suas cláusulas de abertura do art. $5^{\circ}, \S 2^{\circ}$ e $3^{\circ}$, mostra-se um relevante apoio interpretativo para o reconhecimento de uma presunção de não-retrocesso em direitos fundamentais, vez que o Pacto de San Jose da Costa Rica traz proteção à presunção de inocência e - sobretudo assegura normas de ampla garantia destes direitos. Deste modo, não caberia ao STF modificar seu entendimento publicizado no julgamento do HC 84.078, de 2009, que firmou jurisprudência favorável ao cumprimento da pena somente após o trânsito em julgado, retroagindo na proteção de direitos de liberdade, diante dos compromissos internacionais assumidos pelo Estado Brasileiro, devidamente convertidos em norma interna, por conta de expressão previsão constitucional.

\section{REFERÊNCIAS}

ACKERMAN, Bruce. The rise of world constitutionalism. Virginia Law Review, v. 83, n. 4, mai. 1997, p. 771-97.

BOBBIO, Norberto. A Era dos Direitos. Rio de Janeiro: Campus, 1992.

BRASIL. Constituição da República Federativa do Brasil, de 5 de outubro de 1988. Diário Oficial da União. Brasília, 1988. Disponível em: <http://www.planalto. gov.br/ccivil_03/constituicao/constituicao.htm>. Acesso em: 28 out. 2017.

Decreto-Lei no 3.689, de 3 de outubro de 1941. Código de Processo Penal. Diário

Oficial da União. Rio de Janeiro, 1941. Disponível em: <http://www.planalto.gov.br/ccivil_03/decreto-lei/Del3689.htm>. Acesso em: 28 out. 2017.

Supremo Tribunal Federal. HC $\mathrm{n}^{\circ}$ 84.078, Relator: Ministro Eros Grau, Tribunal Pleno. Data do Julgamento: 5 fev. 2009. Diário da Justiça da União. Brasília, DF, 26 fev. 2010. 
〈http://www.stf.jus.br/arquivo/cms/noticiaNoticiaStf/anexo/HC84078voto.pdf $>$. Acesso em: 28 out. 2017.

Supremo Tribunal Federal. HC no 126.292, Relator: Ministro Teori Zavascki, Tribunal Pleno. Data do Julgamento: 17 fev. 2016. Disponível em: < http://redir.stf.jus.br/paginadorpub/paginador.jsp?docTP=TP\&docID=10964246>. Acesso em: 28 out. 2017.

BADARÓ, Gustavo Henrique. Processo Penal. 4ª Ed. São Paulo: RT. 2016.

CARVALHO, Amilton Bueno de. Lei, para que(m)? In: Escritos de Direito e Processo Penal em homenagem ao Professor Paulo Cláudio Tovo. WUNDERLICH, Alexandre (coord.).Rio de Janeiro: Lumen Juris, 2001.

FERRAJOLI, Luigi. Derecho y Razón. Trota: Madrid, 1995.

JACKSON, Vicki. Constitutional engagement in a Transnational Era. New York: Oxford University Press, 2010.

LOPES JUNIOR, Aury. Introdução Critica ao Processo Penal: fundamentos da instrumentalidade Constitucional. Rio de Janeiro: Lúmen Juris, 2006.

.Direito Processual Penal e sua Conformidade Constitucional. Rio de Janeiro: Lúmen Juris, 2007.

MAZZUOLI, Valério de Oliveira. Curso de direitos Humanos. $4^{\circ}$ Ed. Rio de Janeiro: Método, 2017.

MORAES, Alexandre de. Direito Constitucional. São Paulo: Atlas, 2015.

NEVES, Marcelo. Do diálogo entre as cortes supremas e a Corte Interamericana de Direitos Humanos ao transconstitucionalismo na América Latina. Revista de informação legislativa, v. 51, n. 201, p. 193-214, jan./mar. 2014.

OlIVEIRA, Eugênio Pacelli de. Curso de Processo Penal. Belo Horizonte: Del Rey, 2015.

Processo e Hermenêutica na Tutela Penal dos Direitos Fundamentais. Belo Horizonte: Del Rey, 2017. 
PÉREZ LUÑO, Antonio Enrique. Derechos humanos, Estado de derecho y constitución, $5^{\text {a }}$ ed. Madrid, Tecnos, 1995.

PIOVESAN, Flávia. Tratados Internacionais de Proteção dos Direitos Humanos: Jurisprudência do STF. Disponível em: <http://www.dhnet.org.br/direitos/militantes/ flaviapiovesan/piovesan_tratados_sip_stf.pdf>. Acesso em: 05.02.2014.

PRADO, Luiz Régis. Tratado de Direito Penal brasileiro. 2 ed. São Paulo: RT, 2017

RANGEL, Paulo. Direito Processual Penal. Rio de Janeiro: Lúmen Juris, 2010.

SLAUGHTER, Anne-Marie; BURKE-WHITE, William W.. The Future of International Law is Domestic (or, the European Way of Law). Harvard International Law Journal, v. 47, n. 2, p. 327-352, 2006.

TORRES PEREZ, Aida. Conflicts of rights in the European Union: a theory of supranational adjudication. Oxford: Oxford University Press, 2009.

TOURINHO FILHO, Fernando da Costa. Processo Penal. São Paulo: Saraiva, 2000.

ZAFFARONI, Eugenio Raúl. O inimigo no direito penal. Tradução de Sérgio Lamarão.2.ed. Rio de Janeiro: Revan, 2007. 